\title{
BCG SCAR FORMATION @ 3 MONTHS FOLLOWING BCG VACCINATION IN TERM INFANTS @ ACSR GOVT. MEDICAL COLLEGE, NELLORE, ANDHRA PRADESH- A PROSPECTIVE OBSERVATIONAL STUDY
}

\author{
C. Lakshmi Prasanna ${ }^{1}$, P. Satya Prakash²,M. Chowdary Babu³, V. Sagar 4
}

${ }_{1}^{1}$ Assistant Professor, Department of Paediatrics, ACSR Government Medical College, Nellore, Andhra Pradesh, India. ${ }^{2}$ Assistant Professor, Department of Paediatrics, ACSR Government Medical College, Nellore, Andhra Pradesh, India. ${ }^{3}$ Associate Professor, Department of Paediatrics, ACSR Government Medical College, Nellore, Andhra Pradesh, India. ${ }^{4}$ Senior Resident, Department of Paediatrics, ACSR Government Medical College, Nellore, Andhra Pradesh, India.

\section{ABSTRACT}

\section{BACKGROUND}

Tuberculosis is still a challenging global problem and continues to have a significant impact on health care worldwide. $\{1,2\}$ As per global 2018 TB report, in India, every year, an estimated 2.2 lakh children develop TB illness contributing to $22 \%$ of Global TB burden. ${ }^{\{3\}}$ As Tuberculosis (TB) is a serious public health problem, BCG vaccination remains an essential part of TB prevention strategy especially in children. BCG scar is a surrogate marker of vaccination and an important index in the vaccination program. $\{1,2\}$ BCG appears to be a promising tool in the prevention of TB in children. There is considerable variation in BCG scar failure rate data, and correlation between BCG scar and vaccination. We wanted to determine the scar failure rate following BCG vaccination in term infants and birth weight $>2 \mathrm{Kg}$ wt., within the first 3 months following BCG vaccination.

\section{METHODS}

It is a prospective observational study conducted among 120 consecutive infants weighing $>2 \mathrm{Kg}$ attending the immunization clinic of ACSR Government Medical College Hospital. One infant died and 9 could not complete the follow up as per the protocol; hence, 110 infants were included in the final analysis. All babies were administered $0.1 \mathrm{ml}$ of BCG vaccine intradermal as per protocol and examined at 3 months ( 12 week) for scar on follow up. BCG scar size was measured both across and along the arm in millimeter using a plastic ruler and the average was calculated. Statistical analysis was done accordingly.

\section{RESULTS}

Majority (105) (95.45\%) of neonates developed visible scar after 12 wks., of vaccination and 5 (4.5\%) had no visible scar representing scar failure rate of $4.5 \%$. There were $76(69.09 \%)$ males and $34(30.90 \%)$ females. Scar failure rate was $3.9 \%(3)$ in males and 5.8\% (2) in females showing insignificant difference. Babies weighing $>2.5 \mathrm{Kg}$ in the study were $91(82.72 \%)$ and 19 $(17.25 \%)$ were between 2 to $2.5 \mathrm{Kg}$ who had undergone BCG vaccination. Scar failure rate in babies weighing $<2.5 \mathrm{Kg}$ was $10.5 \%$ (3) and 3.2\% (2) in babies weighing > $2.5 \mathrm{Kg}$. Majority 88 (80\%) of infants received vaccination within $72 \mathrm{hrs}$ while 13 (11.80\%) between 3 to 7 days and rest $9(8.18 \%)$ between 7 to 30 days. Scar failure rate was more in babies vaccinated after 7 days $22.2 \%$ (3) compared to babies vaccinated within 7 days $10.1 \%$ (2). Majority of the babies in the study 78 (70.90\%) were on exclusive breast feeds, $11(10 \%)$ were on formula feeds and $21(19.09 \%)$ were on mixed feeds. Scar failure was 18.8\% (2) in formula fed babies and $1.2 \%$ (1) on exclusive breast feeding and 9.5\% (2) on mixed feeding. Out of 110 babies, 75 (68.18\%) babies had scar size $>1 \mathrm{~cm}, 26(23.63 \%)$ had scar size $<1 \mathrm{~cm}$ and 4 (3.63\%) had palpable nodule and no scar $5(4.5 \%)$ representing scar failure rate of $4.5 \%$.

\section{CONCLUSIONS}

Majority of infants (95.45\%) developed a scar at 12 weeks post vaccination. The association between BCG scar and vaccination was highly significant. BCG scar formation was not affected by age or gender. Scar failure rate was less in babies vaccinated within 7 days and birth weight $>2.5 \mathrm{Kgs}$. Scar failure rate was more in formula fed babies than exclusive breast-fed babies.

\section{KEY WORDS}

Term Babies, >2Kg, BCG Vaccination, Scar Failure 12 Weeks

HOW TO CITE THIS ARTICLE: Prasanna CL, Prakash PS, Babu MC, et al. BCG scar formation @ 3 months following BCG vaccination in term infants @ ACSR Govt. medical college Nellore, Andhra Pradesh- a prospective observational study. J. Evolution Med. Dent. Sci. 2019;8(26):2086-2089, DOI: 10.14260/jemds/2019/459

\section{BACKGROUND}

Tuberculosis is still a challenging global problem and continues to have a significant impact on health care worldwide. $\{1,2\}$

'Financial or Other Competing Interest': None.

Submission 08-05-2019, Peer Review 18-06-2019,

Acceptance 24-06-2019, Published 01-07-2019.

Corresponding Author:

Dr. P. Satya Prakash,

Assistant Professor, H. No. 24-3-894,

Dr.Ambedkar Nagar, Dargamitta,

Nellore-524003, Andhra Pradesh, India.

E-mail:catchdrsatya@gmail.com

DOI: $10.14260 /$ jemds $/ 2019 / 459$

\section{(c) $(i)$}

As per global 2018 TB report in India every year an estimated 2.2 lakh children develop TB illness contributing to $22 \%$ of Global TB burden.\{3\} World Tuberculosis Day Theme 2019 "IT'S TIME" showcasing the urgency and time for action. The elimination of TB is a majorly considered in Indian Government's strategic plan of 2017 to 2025.\{4\} The Global strategy of shifting to Zero death by TB cannot happen without focus of TB in children. BCG vaccination remains an essential part of TB prevention strategy especially in children. The BCG vaccine is a live attenuated vaccine strain which produces lifelong cellular immunity against TB and its complications in children including Tuberculous Meningitis which causes serious brain damage. BCG vaccines have also shown to have non-TB benefits in childhood survival rates. 


\begin{tabular}{|c|c|c|}
\hline BCG Scar & Number & Percentage \\
\hline Present & 105 & $95.45 \%$ \\
\hline Absent & 5 & $4.55 \%$ \\
\hline Total & $\mathbf{1 1 0}$ & $\mathbf{1 0 0 \%}$ \\
\hline \multicolumn{3}{|c|}{ Table 1 } \\
\hline
\end{tabular}

\begin{tabular}{|c|c|c|c|}
\hline BCG Scar & Male & Female & Percentage \\
\hline Present & $73(66.36 \%)$ & $32(29.09 \%)$ & $95.45 \%$ \\
\hline Absent & $3(2.72 \%)$ & $2(1.81 \%)$ & $4.55 \%$ \\
\hline Total & $\mathbf{7 6 ( 6 9 . 0 9 \% )}$ & $\mathbf{3 4}(\mathbf{3 0 . 9 0} \%)$ & $\mathbf{1 0 0} \%$ \\
\hline \multicolumn{4}{|c|}{ Table 2. Sex Distribution } \\
\hline
\end{tabular}

\begin{tabular}{|c|c|c|c|}
\hline BCG Scar & Wt. (2-2.5 Kg) & Wt. > 2.5 Kg & Percentage \\
\hline Present & $17(15.45 \%)$ & $88(80 \%)$ & $95.45 \%$ \\
\hline Absent & $2(1.81 \%)$ & $3(2.72 \%)$ & $4.55 \%$ \\
\hline Total & $\mathbf{1 9}(\mathbf{1 7 . 2 7 \% )}$ & $\mathbf{9 1}(\mathbf{8 2 . 7 2} \%)$ & $\mathbf{1 0 0} \%$ \\
\hline \multicolumn{4}{|c|}{ Table 3. Weight Distribution } \\
\hline
\end{tabular}

\begin{tabular}{|c|c|c|c|c|}
\hline BCG Scar & Breast Feeds & Formula Feeds & Mixed Feeds & Percentage \\
\hline Present & $77(70 \%)$ & $9(8.18 \%)$ & $19(17.27 \%)$ & $95.45 \%$ \\
\hline Absent & $1(0.90 \%)$ & $2(1.81 \%)$ & $2(1.81 \%)$ & $4.55 \%$ \\
\hline Total & $\mathbf{7 8 ( 7 0 . 9 0 \% )}$ & $\mathbf{1 1}(\mathbf{1 0} \%)$ & $\mathbf{2 1 ( 1 9 . 0 9 \% )}$ & $\mathbf{1 0 0 \%}$ \\
\hline \multicolumn{5}{|c|}{ Table 4. Type of Feeds } \\
\hline
\end{tabular}

\begin{tabular}{|c|c|c|c|c|}
\hline BCG Scar & $<$ 3 Days & 3 to 7 Days & > 7 Days & Percentage \\
\hline Present & $87(79.09 \%)$ & $11(0.10 \%)$ & $7(6.36 \%)$ & $95.45 \%$ \\
\hline Absent & $1(0.90 \%)$ & $2(1.81 \%)$ & $2(1.81 \%)$ & $4.55 \%$ \\
\hline \multicolumn{6}{|c|}{ Table 5. Day of Vaccination } \\
\hline
\end{tabular}

\begin{tabular}{|c|c|c|}
\hline Size of the Scar & Scar Present & Percentage \\
\hline$>1 \mathrm{~cm}$ & 75 & $68.18 \%$ \\
\hline$<1 \mathrm{~cm}$ & 26 & $23.63 \%$ \\
\hline Palpable Nodule & 04 & $3.63 \%$ \\
\hline No Scar & 5 & $4.54 \%$ \\
\hline Total & $\mathbf{1 1 0}$ & $\mathbf{1 0 0} \%$ \\
\hline \multicolumn{3}{|c|}{ Table 6. Size of Scar } \\
\hline
\end{tabular}

Recent immunologic studies have shown that BCG induces epigenetic modulations in monocytes and increased responsiveness against unrelated stimuli, thus providing a plausible immunological mechanism behind the beneficial nonspecific effects.[5,6] BCG scar is a surrogate marker of vaccination and an important index in the vaccination program. However, scar failure is a well-known phenomenon with prevalence varying from $1 \%$ to $20 \%$ in term infants in different studies worldwide.\{7-8\} Apart from protection against severe forms of TB, BCG also has a non-TB-related beneficial effect on child survival. Studies suggesting association of BCG scar with decreased childhood mortality in developing countries have rekindled the interest on BCG scar. ${ }^{99\}}$ The true magnitude of scar failure and whether the scar negative infants need to be monitored remains unclear. Our study aims in scar conversion following BCG vaccination and its efficacy within first 3 months of life in our center.

\section{METHODS}

This prospective Observational study was carried out at the immunization clinic of ACSR GOVT Medical college hospital Nellore after obtaining permission from the Institutional Ethics Committee. The parents were fully informed about the study, its duration, follow up and written consent was obtained from them and only those infants whose parents consented and agreed to participate in the study were recruited.

\section{Study Period}

From $1^{\text {st }}$ Nov. 2017 to $31^{\text {st }}$ Jan. 2018.

\section{Inclusion Criteria}

Our study group population was the term babies delivered in our hospital weighing $>2 \mathrm{Kg}$ were recruited for study. Since it is short period observational study our target population was 100.

\section{Exclusion Criteria}

- Preterm \& Term babies weighing less than $2 \mathrm{Kg}$.

- Babies born to HIV mothers.

- Family history of TB.

- Syndromic and chromosomal malformations.

- Suffering from any acute illness.

All study subjects after obtaining consent were administered $0.1 \mathrm{ml}$ of BCG by a single trained staff nurse on the left arm just above the insertion of deltoid muscle intradermally with a 26-gauge needle and tuberculin syringe. BCG vaccine containing Moscow BCG-I (Russian) strain manufactured at the Green Signal Bio Pharma Ltd. Gummidi Poondi- Tamilnadu was used. This vaccine was licensed in India with licence no. TN00002482 and subsequently prequalified by WHO for use in developing countries. The freeze-dried vaccine was reconstituted with normal saline and was used within 3 hours. All cold chain precautions were maintained. All vaccinated babies were inspected for the presence of a wheal by one of the investigators. Simultaneously, oral polio vaccine and hepatitis B vaccines were also administered as per the national immunization schedule. The parents were given a follow up date 3 months ( +1 week) from the date of vaccination. On follow up, infants were examined for the presence of scar or local reaction at the vaccination site. BCG scar size was measured both across and along the arm in millimeter using a plastic ruler and the average was calculated.

\section{Statistical Analysis}

Data was described as mean \pm SE and \%age. Software used for data analysis was SPSS 16.0 (Statistical Package for Social Sciences) and MS Excel.

\section{RESULTS}

Of the 120 neonates $>2 \mathrm{Kg}$ recruited in the study one infant died at home due to unrelated causes and 9 could not complete the follow up as per the protocol hence 110 infants were included in final analysis. Majority 105(95.45\%) of neonates developed visible scar after 12 wks., of vaccination and $5(4.5 \%)$ had no visible scar representing scar failure rate of $4.5 \%$. There were $76(69.09 \%)$ males and $34(30.90 \%)$ females. Scar failure rate was 3.9\% (3) in males and 5.8\% (2) in females showing not much difference. Babies weighing $>2.5 \mathrm{Kg}$ in the study were $91(82.72 \%)$ and $19(17.25 \%)$ were between 2 to $2.5 \mathrm{Kg}$ who had undergone BCG Vaccination. Scar failure rate in babies weighing $<2.5 \mathrm{Kg}$ was $10.5 \%$ (3) and $3.2 \%$ (2) in babies weighing > $2.5 \mathrm{Kg}$. Majority 88(80\%) of infants received vaccination within 72 hrs., while 13 (11.80\%) between 3 to 7 days and rest $9(8.18 \%)$ between 7 to 30 days. Scar failure rate was more in babies vaccinated after 7 days $22.2 \%$ (3) compared to babies vaccinated within 7 days $10.1 \%$ (2). MAJORITY of the babies in the study 78 $(70.90 \%)$ were on exclusive breast feeds, $11(10 \%)$ were on formula feeds and 21(19.09\%) were on mixed feeds. Scar failure was $18.8 \%$ (2) in formula fed babies and $1.2 \%$ (1) on 
exclusive breast feeding and 9.5\% (2) on mixed feeding. Out of 110 babies $75(68.18 \%)$ babies had scar size $>1 \mathrm{~cm}, 26$ (23.63\%) had scar size $<1 \mathrm{~cm}$ and $4(3.63 \%)$ had palpable nodule and no scar $5(4.5 \%)$ representing scar failure rate of $4.5 \%$.

\section{DISCUSSION}

The World Health Organisation (WHO) estimates are that 1 million children $(<15$ years) currently suffer from TB worldwide, and that 239,000 die each year. ${ }^{88\}}$ Nearly $10 \%$ of cases reported to RNTCP are from children under 14 yrs., of age. $\{10\}$ Due to the high burden of TB in developing countries, BCG vaccination continues to remain an important armamentarium in the prevention of serious childhood TB. It is one of the oldest and most commonly used vaccines despite the controversies surrounding it. BCG is generally considered to protect against tuberculous meningitis and miliary $\mathrm{TB}$ among infants and young children. The Global strategy of shifting to Zero death by TB cannot happen without focus of TB in children. $\{1,2\}$ BCG appears a promising tool in prevention of TB in children and our study aims in scar conversion following BCG vaccination. $\{3\}$ As per WHO recommendation, BCG vaccine should be administered as soon as possible after birth and before 1 month of age for maximum protection. $\{4\}$

In the present study out of 110 babies, majority $105(95.45 \%)$ of babies developed visible scar after 12 wks., of vaccination and $5(4.5 \%)$ had no visible scar representing scar failure rate of $4.5 \%$. This was comparable to other Indian studies on term infants by Rani $(10 \%)^{\{2\}}$ and Lakhar $(6.1 \%) .\{10\}$ Majority of the babies in the study $78(70.90 \%)$ were on exclusive breast feeds, $11(10 \%)$ were on formula feeds and 21 (19.09\%) were on mixed feeds. Scar failure was $18.8 \%$ (2) in formula fed babies and $1.2 \%$ (1) on exclusive breast feeding and $9.5 \%$ (2) on mixed feeding thus showing more scar failure in formula fed babies. In this study majority $88(80 \%)$ of infants received vaccination within 72 hrs., while $13(11.80 \%)$ between 3 to 7 days and rest $9(8.18 \%)$ between 7 to 30 days. There is significant difference in the formation of scar those vaccinated with in 7 days and more than 7 days (10.1\% VS $22.2 \%)$ unlike Surekha et al study where scar failure was more common in infants vaccinated within 48 hours. $\{11\}$ In our study higher scar failure was seen in babies with birth weight less than $2.5 \mathrm{Kg}$ than $>2.5 \mathrm{Kg}(10.92 \%$ vs $3.2 \%)$. Higher scar failure rate (55\%) has been reported in low birth weight babies from India.\{12\} A study from Pakistan reported scar failure rate of $19.6 \%,\{13,14\}$ whereas the studies from LIMA Peru, $\{10\}$ Nigeria, ${ }^{\{15\}}$ and Brazil $\{16\}$ showed much lower scar failure rate of $1.4 \%, 3.7 \%$ and $3.1 \%$, respectively. This difference could be accounted for by variability in the study design and differences in the demographic characteristics of subjects. Development of BCG scar depends on the strain, injected dose and technique of administration. $\{17\}$ Other factors like quality of vaccine, proper transport, storage and undiagnosed underlying immune disorder in infants are also responsible for the absence of scar formation. $\{12\}$ Majority $68.18 \%$ had scar size > $10 \mathrm{~mm} @ 12$ wks. The mean scar size in the study 4.9 observed by Aggarwal et al was $4.93 \mathrm{~mm}^{\{12\}}$ and by Dhanwade et al $4.8 \mathrm{~mm} .\{18,19\}$
The absence of scar should not remain a mere observation of parents but should be part of health surveys. Presently there is no universal recommendation for BCG vaccination in scar negative infants. Infants who fail to develop a scar is a matter of concern and whether these infants need to be followed and evaluated remain unresolved. Recent studies have suggested that BCG scar and positive tuberculin tests are associated with better survival in early childhood in countries with high child hood mortality.\{20,21\} The beneficial effect of BCG is attributed to the non-specific enhancement of both antibody and cellular immune responses. Considering these studies, it seems prudent to revaccinate children without a BCG scar in developing countries with high under 5 mortality. There is a need for proper evaluation and monitoring of the BCG vaccination programs.

\section{CONCLUSIONS}

Majority of infants (95.45\%) developed a scar at 12 weeks post vaccination. The association between BCG scar and vaccination was highly significant. BCG scar formation was not affected by age or gender. Scar failure was more in babies vaccinated after 7 days of life and birth wt. $<2.5 \mathrm{Kg}$. Scar failure rate was more in formula fed babies than exclusive breast-fed babies. Larger studies are required to reveal the true magnitude of the problem. Regular evaluation of BCG vaccination programmes is recommended.

\section{Limitations}

Small sample size is a key limitation of the study. Moreover, we have followed up the infants up to 12 weeks only. It is possible that positivity of scar and efficacy of vaccine depends on dose, route of administration, storage and transport. BCG scar might have increased if we had longer follow-up at least for 6 months. Tuberculin testing after 6 months of these babies would have more accurately determined the efficacy of BCG vaccination.

\section{ACKNOWLEDGEMENTS}

We acknowledge the staff in Department of Paediatrics, ACSR GMC Hospital, Nellore, A. P., including the research projects manager Mr. Bhakthavastalam. We would also like to acknowledge Dr. M. Chowdary Babu, Associate Professor, Paediatrics, Dr. Ravi Prabhu, Professor, SPM, Dr. Sri Hari, Principal, for their continuous support and guidance.

\section{REFERENCES}

[1] Santiago EM, Lawson E, Gillenwater $\mathrm{K}$, et al. A prospective study of bacillus Calmette-Guérin scar formation and tuberculin skin test reactivity in infants in Lima, Peru. Pediatrics 2003;112(4):e298.

[2] Rani SH, Vijayalaksmi V, Sunil K, et al. Cell medicated immunity in children with scar-failure following BCG Vaccination. Indian Pediatrics 1998;35(2):123-7.

[3] Sherjil A, Iqbal CJ. Absence of scar formation in infants after BCG vaccination. Professional Med J 2006;13:637-41.

[4] Atimati AO, Osarogiagbon OW. Prevalence of BCG scar among BCG-vaccinated children in a southern Nigeria tertiary hospital. Niger J Paed 2014;41(3):229-33. 
[5] Kleinnijenhuis J, Quintin J, Preijers F, et al. Bacille Calmette-Guerin induces NOD2-dependent nonspecific protection from reinfection via epigenetic reprogramming of monocytes. Proc Natl Acad Sci U S A 2012;109(43):17537-42.

[6] Aaby P, Benn CS. Saving lives by training innate immunity with bacille Calmette-Guerin vaccine. Proc Natl Acad Sci U S A 2012;109(43):17317-8.

[7] Roth A, Gustafson P, Nhaga A, et al. BCG vaccination scar associated with better childhood survival in Guinea-Bissau. Int J Epidemiol 2005;34(3):540-7.

[8] Garly ML, Martins CL, Bale C, et al. BCG scar and positive tuberculin reaction associated with reduced child mortality in West Africa. A non-specific beneficial effect of BCG? Vaccine 2003;21(21-22):2782-90.

[9] Faridi MM, Kaur S, Krishnamurthy S, et al. Tuberculin conversion and leukocyte migration inhibition test after BCG vaccination in newborn infants. Hum Vaccine 2009;5(10):690-5.

[10] Lakhkar BB. Neonatal BCG vaccination and scar success. Indian Pediatr 1995;32(12):1323.

[11] Camargos P, Ribeiro Y, Teixeira A, et al. Tuberculin skin reactivity after neonatal BCG vaccination in preterm infants in Minas Gerais, Brazil, 2001-2002. Rev Panam Salud Publica 2006;19(6):403-7.

[12] Aggarwal A, Dutta AK. Timing and dose of BCG vaccination in infants as assessed by post vaccination tuberculin sensitivity. Indian Pediatr 1995;32(6):6359.
[13] Ferreira AA, Bunn-Moreno MM, Sant'Anna CC, et al. BCG vaccination in low birth weight newborns: analysis of lymphocyte proliferation, IL-2 generation and intradermal reaction to PPD. Tuber Lung Dis 1996;77(5):476-81.

[14] Gupta P, Faridi MM, Shah D, et al. BCG reaction in twin newborns: effect of zygosity and chorioncity. Indian Pediatr 2008;45(4):271-7.

[15] Ten Dam HG. Research on BCG vaccination. Adv Tuberc Res 1984;21:79-106.

[16] Vidal ML, Hortelano JG, Roman E. Follow-up of BCG through mantoux reaction. In: Casel $M$, edr. Mycobacteria of clinical interest. Amsterdam: Elseiver Science Publishers BV 1986: p. 130-2.

[17] Das SK, Gautam KD, Mehrotra ML, et al. Timing of BCG vaccination in infants. Indian J Tuberc 1980;27:63-5.

[18] Kaur S, Faridi MM, Agarwal KN. BCG vaccination reaction in low birth weight infants. Indian J Med Res 2002;116:64-9.

[19] Ahamd SR, Bokhari SY. Anergy in pulmonary tuberculosis. Pakistan J Chest Med 2000;6:5-9.

[20] Thayyil-Sudhan S, Kumar A, Singh M, et al. Safety and effectiveness of BCG vaccination in preterm babies. Arch Dis Child Fetal Neonatal Ed 1999;81(1):F64-6.

[21] Shen CM, Soong WJ, Jeng MJ, et al. Tuberculin response in infants six months after an intradermal Bacille Calmette-Guerin vaccination. Fu-Jen Journal of Medicine 2007;5:115-21. 